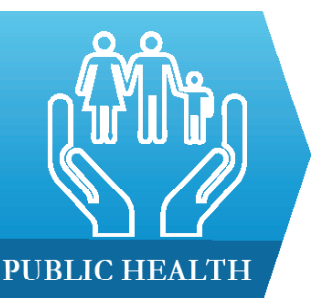

1) Clinic of Social and Family Medicine, School of Medicine, University of Crete, Heraklion, Crete, Greece

2) Department of Political Science, University of Crete, Rethymno, Crete, Greece

\title{
Discussing issues of health promotion and research in the context of primary care during the ongoing austerity period: an exploratory analysis from two regions in Greece
}

Vicky Sbarouni ${ }^{1}$, Elena Petelos ${ }^{1}$, Apostolos Kamekis ${ }^{1}$, Stylianos Ioannis Tzagkarakis ${ }^{2}$, Emmanouil K. Symvoulakis ${ }^{1}$, Christos Lionis ${ }^{1}$

\begin{abstract}
Background. In Greece, both Primary Health Care (PHC) system and National Health System (NHS) in general, were plagued by several inefficiencies even prior to the financial crisis; the imposed austerity measures dramatically worsened the level of health provision and access, especially for vulnerable social groups, resulting in an exacerbation of existing disparities and access gaps.
\end{abstract}

Aim and methods. The current branch study was conducted in two regions of Greece, namely Crete and Epirus, with the main aim of eliciting responses to gather baseline information regarding crucial PHC-related aspects, using questionnaires with dichotomous questions. Directors or managers (physicians who have been assigned administrative/governance duties), of the Primary Health Care Centres (PHCCs) in two Greek geographic and administrative regions of Crete and Epirus, were invited to participate and to contribute to the investigation of issues on the provision of prevention and health promotion services, e-health topics and primary care research. Thirty directors/managers were approached and twenty-eight agreed to participate. Data processing and analysis of the responses was performed for the completed questionnaires.

Results. Data analysis did not demonstrate a surprisingly substantial deviation in the average score of positive responses of directors/managers in the PHCCs of Crete in comparison to those of directors/managers in the PHCCs of Epirus. The findings show that several gaps exist in terms of prevention and health promotion resources and activities in both regions, while e-health, electronic health record (EHR) and telemedicine services are poorly developed.

Conclusion. The study confirms that the Greek PHC is characterized by several inefficiencies, which may affect the quality of the services provided. An overall deficit has been emerged for PHCCs in both regions, a fact that indicates crucial points lacking in terms of overall $\mathrm{PHC}$ provision, thus adversely impacting upon living conditions, health quality and prevention.

Keywords: primary health care, health promotion, prevention, research

\section{Background}

Good PHC leads to an overall Received in revised form: 04.06.2019 Accepted: 16.09.2019

Address for correspondence: symvouman@yahoo.com

This work is licensed under a Creative Commons Attribution-NonCommercialNoDerivatives 4.0 International License improvement of the whole healthcare system, addressing the needs of patients in an equitable manner with quality services. Given the increasing prevalence of multimorbidity in the context of 'aged communities', as well as the increased healthcare costs, PHC represents a promising way for addressing care challenges in terms of equity and equality in care provision [1]. It is important to note that such objective can only be achieved by respecting community needs, as for example, by coordinating first and equal healthcare contact to all and offering appropriate and accessible care to those with complex and chronic care problems [2]. 
Prevention and health promotion are important elements of a well-designed system, as long as they extend beyond simply targeting early diagnosis and isolated efforts, and are in place to effect change much before a disease becomes clinically evident. Low performance scores have been reported in a European study some years ago in several countries, including Greece [3]. Self-management support seems to be the most relevant modality, especially in deprived populations [4]. To ensure seamless and effective health care in any given system, each level of care should be equipped with the appropriate resources to fulfil its proper role; there should be a continuous effort to invest into healthy lifestyle habits with interventions mainly coordinated through focused PHC-driven initiatives taking into consideration local needs and wider public health considerations. PHC research can hopefully lead to the development of empirical models that may offer guidance for countries with limited resources to discover local strengths and find innovative solutions to address substantial limitations [5].

PHC can offer effective delivery of health services to citizens which include: first-contact access, long-term focus on the patient rather than disease-focused care, comprehensiveness of services provided and coordination of the services where they are needed [6-8]. However, recent reports from extensive European collaborative projects including those from the QUALICOPC project of NIVEL indicate that the quality performance of PHC services in Greece is still low [9]. Furthermore, PHC reform failure - a result of half-measures remaining incomplete given political leaders with very different agendas and differing priorities in quick succession - was masked by sporadic actions leading to further spending. However, the global financial crisis has had a major impact on the Greek economy and society as welfare state policies have met large budgetary cuts, as a result of which all services provided in this context have been challenged resulting in previously incomplete implementation or half-measures being highlighted and leaving large population groups, particularly the vulnerable groups, very much exposed to exacerbated inequalities. There is ample evidence that vulnerable groups are the most affected among the social groups affected, as their health has worsened since the occurrence of the financial crisis [10-12]. Increasing unemployment, which is the highest among the EU Member-States, funding cuts in social policy and poor resources, adversely impact access to health care, which has become even more rudimentary $[13,14]$.

Certain articles have been published during the austerity period highlighting the necessity for PHC reform $[15,16]$. However, there is still lack of primary data to inform and facilitate the evaluation process and promote rational thinking about which changes to incorporate and which model to adopt in the context of the PHC reform that is currently under discussion for these regions and for the whole of Greece. A research evaluation project to address the quality and the encountered problems in rural primary care in Greece has been designed and implemented some years ago, with the first qualitative study branch results already reported [17].

The current report offers brief information on prevention, health promotion and PHC research activities that have been undertaken in the PHCCs in the two Greek regions, Crete and Epirus; these are issues that remain largely, and for years, neglected in the Greek PHC setting and that have been further pushed aside or even marginalized under the conditions imposed in the austerity period. This study is anticipated to inform stakeholders and policy makers on the importance of these topics in order to sustain PHC reform efforts. The objective of this short report is to communicate the findings from this branch study regarding prevention, e-health and research issues in Crete and Epirus in the context of PHC provision.

\section{Methods \\ Setting}

The current study collected data from two geographical and administrative regions that represent two distinct rural settings, Crete - the largest island, and Epirus - a large mountainous region, at the beginning of the financial crisis. The region of Crete has fourteen PHCCs and the region of Epirus sixteen PHCCs, with total population sample coverage of 283,695 out of 621,340 people for Crete and 195,200 out of 350,000 people for Epirus, respectively, thus, comprising rather a large catchment area. The data collection was performed between December 2008 and June 2009 and was part of an ongoing larger project launched by the Clinic of Social and Family Medicine of the University of Crete (CSFM, UoC) in collaboration with the Department of Political Science of the UoC and the National School of Public Health (NSPH) of Greece with the greater aim of detailed mapping of the PHCC services provided in Greece [17].

\section{Participants and sampling}

Directors and managers of PHCCs in Crete and Epirus were invited to participate and to contribute to this effort with their yes/no responses to pre-tested questionnaires. Written material informing participants about the aim of the study and confidentiality issues was given, and the voluntary nature of participation was explicitly explained. All the participating directors were asked to sign an informed consent form prior to the questionnaire completion.

\section{Tools}

Twelve dichotomous questions were prepared to target prevention, health promotion services, e-health resources and $\mathrm{PHC}$ research and were tested for assessing content validity and linguistic accuracy. Trained researchers administered the questionnaires, while completion took place on the surveyed PHCC locations. Data processing 
was performed using the SPSS 20.0 statistical package (SPSS Inc., Chigaco, IL, USA).

\section{Ethics}

The Ethics Committee of the University Hospital of Crete offered approval for this study (Protocol No 9919) and clearance to proceed was obtained by the Ministry of Health and Solidarity (Greece).

\section{Results}

Thirty directors/managers were approached with twenty-eight agreeing to participate: twelve in Crete and sixteen in Epirus, $85.71 \%$ and $100 \%$, respectively, of those approached. According to data analysis of the PHCC directors'/managers' positive responses, there is no surprisingly meaningful variation; as the questionnaire was dichotomous, response mapping depended on the judgment being reported, namely yes/no reflect the positive/negative dichotomy, between the PHCCs of Crete and Epirus.

The findings (Table I) indicate several gaps in prevention and health promotion in both regions. In Crete, $8 / 12(67 \%)$ of the respondents stated that women have been recorded as having one Papanicolaou (Pap smear) test in comparison with Epirus respondents $(25 \%, 4 / 16)$. PHCCs in both regions seem not to take significant initiatives on prevention and health promotion for pregnant smokers, as only 6/12 (50\%) of the PHCCs from Crete and 3/16 (19\%) from Epirus record smoking habits during pregnancy and, respectively, $5 / 12(42 \%)$ from Crete and 2/16 (12.5\%) from Epirus organize sessions for smoking cessation among pregnant smokers (Table I).

Table I. Responses of PHCC directors on prevention, e-health and research topics.

\begin{tabular}{|c|c|c|c|c|}
\hline \multirow{9}{*}{$\begin{array}{l}\text { PREVENTION } \\
\text { AND HEALTH } \\
\text { PROMOTION }\end{array}$} & Variables & Crete & Epirus & Total $(n=28)$ \\
\hline & 1. Does your PHCC record smoking habits during pregnancy? & $\begin{array}{l}50 \% \\
6 / 12\end{array}$ & $\begin{array}{l}19 \% \\
3 / 16\end{array}$ & 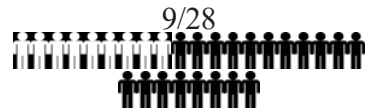 \\
\hline & $\begin{array}{l}\text { 2. Does your PHCC organize sessions for smoking cessation } \\
\text { among pregnant smokers? }\end{array}$ & $\begin{array}{l}42 \% \\
5 / 12\end{array}$ & $\begin{array}{c}12.5 \% \\
2 / 16\end{array}$ & 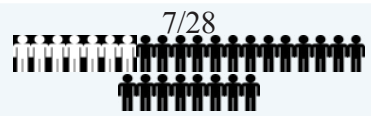 \\
\hline & $\begin{array}{l}\text { 3. Does your PHCC record meetings for breastfeeding } \\
\text { organized before and after pregnancy? }\end{array}$ & $\begin{array}{l}67 \% \\
8 / 12\end{array}$ & $\begin{array}{l}25 \% \\
4 / 16\end{array}$ & 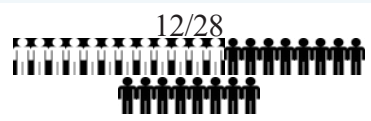 \\
\hline & $\begin{array}{l}\text { 4. Has it been recorded at least one Pap test for active women } \\
\text { and patients of the clinic for } 2 \text { consecutive years? }\end{array}$ & $\begin{array}{l}67 \% \\
8 / 12\end{array}$ & $\begin{array}{l}25 \% \\
4 / 16\end{array}$ & 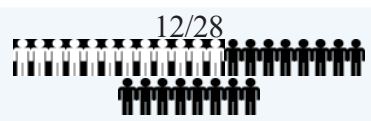 \\
\hline & $\begin{array}{l}\text { 5. Does your PHCC record information on whether women } \\
\text { over } 50 \text { are referred or advised to do a mammography at least } \\
\text { every } 2 \text { years? }\end{array}$ & $\begin{array}{l}58 \% \\
7 / 12\end{array}$ & $\begin{array}{c}81 \% \\
13 / 16\end{array}$ & mingminging \\
\hline & $\begin{array}{l}\text { 6. Does your PHCC record information about whether } \\
\text { patients over } 65 \text { years old are invited to receive or have } \\
\text { received influenza vaccine within the past } 12 \text { months? }\end{array}$ & $\begin{array}{c}83 \% \\
10 / 12\end{array}$ & $\begin{array}{l}87.5 \% \\
14 / 16\end{array}$ & 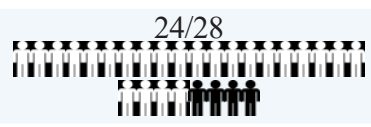 \\
\hline & $\begin{array}{l}\text { 7. Do the visits of healthy children during the first } 2 \text { years } \\
\text { of their life typically include measuring the alignment of the } \\
\text { eyes? }\end{array}$ & $\begin{array}{l}42 \% \\
5 / 12\end{array}$ & $\begin{array}{l}46.7 \% \\
7 / 15\end{array}$ & 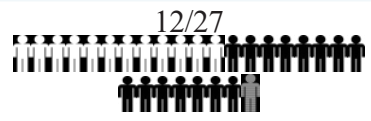 \\
\hline & $\begin{array}{l}\text { 8. Do the visits of healthy children during the first } 2 \text { years of } \\
\text { their life usually include measurement sensitivity to auditory } \\
\text { stimuli? }\end{array}$ & $\begin{array}{l}50 \% \\
6 / 12\end{array}$ & $\begin{array}{l}47 \% \\
7 / 15\end{array}$ & 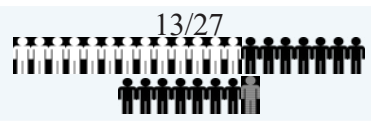 \\
\hline \multirow{2}{*}{ E-HEALTH } & $\begin{array}{l}\text { 9. Does the consulting room of your PHCC have electronic } \\
\text { medical record? }\end{array}$ & $\begin{array}{l}33 \% \\
4 / 12\end{array}$ & $\begin{array}{l}0 \% \\
0 / 16\end{array}$ & 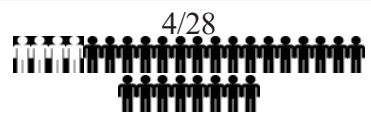 \\
\hline & $\begin{array}{l}\text { 10. Does your PHCC have infrastructure for telemedicine } \\
\text { services in your unit? }\end{array}$ & $\begin{array}{c}50 \% \\
4 / 8\end{array}$ & $\begin{array}{l}29 \% \\
4 / 14\end{array}$ & 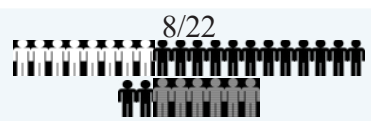 \\
\hline \multirow{2}{*}{ RESEARCH } & 11. Does your PHCC participate in research programs? & $\begin{array}{l}20 \% \\
2 / 10\end{array}$ & $\begin{array}{l}20 \% \\
3 / 15\end{array}$ & IIIHitiving \\
\hline & $\begin{array}{l}\text { 12. Does your PHCC organize and implement research } \\
\text { programs? }\end{array}$ & $\begin{array}{l}20 \% \\
2 / 10\end{array}$ & $\begin{array}{l}13 \% \\
2 / 15\end{array}$ & 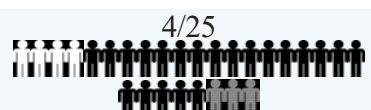 \\
\hline
\end{tabular}


One of the factors that emerged from this survey (Table I) is that telemedicine services are not yet provided in most of the PHCCs in either region (50\%, 4/8-missing values: 4, coverage in the region of Crete and $29 \%$, 4/14-missing values:2, in the region of Epirus). Furthermore, electronic medical records are not available in any PHCC of Epirus and only in four PHCCs in Crete (Table I). Only 20\% (5/25-missing values: 1) of PHCCs in Crete and Epirus are actively involved in research activities (Table I). Obtained responses indicate that only 13\% (2/15-missing values: 1$)$ of Epirus and 20\% (2/10-missing values: 2$)$ of Crete PHCCs organize and implement research projects (Table I). It should be mentioned that there is a different number of missing values for some questions separately. For further details see Table I.

\section{Discussion}

\section{Main findings}

This exploratory analysis indicates that the majority of the PHCCs do not have extensively targeted prevention and health promotion programs in place, as, for example, demonstrated by the fact they do not organizse sessions for smoking cessation among pregnant smokers and there is no systematic recording of smoking habits during pregnancy. While there are high levels of tobacco use in Greece, specific initiatives aiming at developing interventions to overcome existing barriers on tobacco users' PHC assistance have only been conducted recently $[18,19]$. Our exploratory data show that e-health applications and research are not an integral part of PHCC activities. By contrast, most PHCCs record whether women over 50 are referred or advised for mammography at least every 2 years. Most over 65-year olds are also invited for or have received the influenza vaccine within the past 12 months.

\section{Keys issues emerging from the study}

It turns out that the quality of healthcare services has been further impacted upon due to protracted hiring freeze for filling recently 'widowed' positions (by early retirement) and a few newly created positions [13]. It is expected that impeded access for vulnerable social groups in the provision of PHC services or medicines leads to potential risks in terms of patient safety, and can adversely impact upon the overall wellbeing of individuals and community groups [20]. Therefore, mitigating measures and reduction in quality and funding of social provision increases unmet healthcare needs while further challenge the - already low - quality of everyday life [14,21]. Available data show that waiting times to access appropriate therapies and services increased following the outset of the financial crisis, even for important oncology care cases, posing significant risks for patients [22].

The current period is characterized as the era of e-applications aiming to improve the overall wellbeing of people. Therefore, the promotion of e-health supporting social service innovations in health care, relevant initiatives and appropriate resourcing and supporting structures is crucial, as it can increase the efficiency of the healthcare system and reduce costs $[23,24]$. Thus, it may be stated that it is imperative for any reform to focus on an integrated and modern system, including telemedicine services and use the new technologies available across the spectrum of PHC [25]. Monitoring PHC outcomes can be a useful tool to explore specific inefficiencies the time that they occur and offer important feedback [26,27]. Quality control points may help to identify and overcome efficiency gaps more readily [28]. Promoting research that offers information on health issues is another determinant that can help PHCCs to address the current challenges. Gathering information about geo-specific health needs can be a rational way for making PHCCs, each and all, prone to change towards quality improvement of their services.

\section{Limitations}

We successfully gathered 'sensitive', though limited, information from the vast majority of the PHCC directors/managers. From the thirty (30) PHCC managers/ directors invited to participate, twenty eight (28) finally accepted to participate in the survey, but there are totally 14 missing values in questions 7 ( 1 missing), 8 (1 missing), 10 (6 missing), 11 (3 missing) and 12 (3 missing) depicted in Table I. Although the sample of this survey is limited (28 directors/managers of 2 Greek regions), there is a balancing effect by the fact that directors represent, due to their extensive responsabilities, reliable messengers of the issues that PHCCs encounter.

It is widely accepted that the promoting research leads to knowledge generation contributing towards the amelioration of the standard of living. Our findings are not easily generalized and we cannot extrapolate beyond the two regions given the overall heterogeneity. However, an overall deficit in the PHCCs studied in this article, in both regions, has been identified, confirming already reported PHC deficiencies [17].

Using percentile expressions is not an ideal way to describe data because of the limited numbers, but they are used in order to provide a direct comparison between the results of two geographical areas. This survey has been conducted during the first year of the economic recession in Greece and it is worth revisiting similar research questions and fields today, after years of attempt at reforming, budget cuts and much national 'anxiety'.

\section{Conclusions}

It has been demonstrated that there are certain distinct commonalities across these two very important yet distinct geographical and administrative regions, with ample room for improvement in terms of PHC provision. Furthermore, as it is widely accepted, the Greek PHC encounters several administrative, financing and organizational problems 
affecting the quality of services; PHC could greatly benefit from state-level structural changes. Multistakeholder discussions under the aegis of the World Health Organization (WHO) regarding necessary reforms underscore need for immediate improvement [29]. One solution to this issue may be the development of more flexible primary groups along with legislative acts delegating power and fund allocation to regional administrative authorities. These policies offer opportunities to create community-oriented healthcare services and networks that can help preserve the quality of clinical practice [15]. Therefore, there is an urgent need for studies that will elicit further and current information about the rest of the regions and that could help inform the undergoing reform of the institutional and administrative framework of the Greek PHC system. PHC should be more 'present' and 'friendly' to all Greek citizens.

\section{Acknowledgements}

As part of a larger study that the Ethics Committee of the University Hospital of Crete approved (Protocol no. 9919/2007), the authors acknowledge and thank the following professionals, namely: Agoras E, Alevizakou A, Batsis K, Dimitrakopoulos N, Drakos D, Gerantoni E, Kala E, Kambitaki E, Kassimatis P, Katsios E, Katsiou N, Kortzis M, Kostoula K, Kourti T, Ktistakis G, Kristis C, Mitsakou P, Nastas P, Papaharalambous P, Papakosma E, Papanikolaou T, Saridakis A, Stamatis G, Stratis S, Teisen A, Theodorou A, Tsaka S, Vartziotis A, Vasilakis E and Venetis M. Authors also CSFM collaborators on technical aspects and interviews: Antoniadou E, Antoniou M, Kokolodimitraki C, Koukosias N, Moustaka A and Vova X. and, all who anonymously helped with this effort.

\section{References}

1. Starfield B. Global health, equity, and primary care. J Am Board Fam Med. 2007;20:511-513.

2. Starfield B, Shi L, Macinko J. Contribution of primary care to health systems and to health. Milbank Q. 2005;83:457502.

3. Brotons C, Björkelund C, Bulc M, Ciurana R, GodyckiCwirko M, Jurgova E, et al. Prevention and health promotion in clinical practice: the views of general practitioners in Europe. Prev Med. 2005;40:595-601.

4. Koetsenruijter J, van Eikelenboom N, van Lieshout J, Vassilev I, Lionis C, Todorova E, et al. Social support and self-management capabilities in diabetes patients: An international observational study. Patient Educ Couns. 2016;99:638-643.

5. Lionis C, Symvoulakis EK, Vardavas CI. Implementing family practice research in countries with limited resources: a stepwise model experienced in Crete, Greece. Fam Pract. 2010;27:48-54.

6. Souliotis K, Lionis C. Creating an integrated health care system in Greece: a primary care perspective. J Med Syst.
2004;28:643-652.

7. Lionis C, Symvoulakis EK, Markaki A, Vardavas C, Papadakaki M, Daniilidou N, et al. Integrated primary health care in Greece, a missing issue in the current health policy agenda: a systematic review. Int J Integr Care. 2009;30:e88.

8. Wonca Europe. The European Definition of General Practice/Family Medicine, 2011. Available from: http:// www.woncaeurope.org/gp-definitions.

9. Schäfer WL, Boerma WG, Murante AM, Sixma HJ, Schellevis FG, Groenewegen PP. Assessing the potential for improvement of primary care in 34 countries: a crosssectional survey. Bull World Health Organ. 2015;93:161168.

10. Eurofound. Third European Quality of Life Survey - Quality of life in Europe: Impacts of the crisis. Luxembourg: Publications Office of the European Union, 2012. Available from: https://www.eurofound.europa.eu/publications/report/ 2012/quality-of-life-social-policies/quality-of-life-in-europeimpacts-of-the-crisis

11. Vandoros S, Hessel P, Leone T, Avendano M. Have health trends worsened in Greece as a result of the financial crisis? A quasi-experimental approach. Eur J Public Health. 2013;23:727-731.

12. Zavras D, Zavras AI, Kyriopoulos II, Kyriopoulos J. Economic crisis, austerity and unmet healthcare needs: the case of Greece. BMC Health Serv Res. 2016;15:309.

13. Kentikelenis A, Papanicolas I. Economic crisis, austerity and the Greek public health system. Eur J Public Health. 2012;22:4-5.

14. Eurofound. Access to healthcare in times of crisis. Luxembourg: Publications Office of the European Union, 2014. Available from: https://www.eurofound.europa.eu/ publications/report/2014/quality-of-life-social-policies/ access-to-healthcare-in-times-of-crisis

15. Kousoulis A, Symvoulakis E, Lionis C. What Greece can learn from UK primary care experience and empirical research. Br J Gen Pract. 2012;62:543.

16. Tsiachristas A, Lionis C, Yfantopoulos J. Bridging knowledge to develop an action plan for integrated care for chronic diseases in Greece. Int J Integr Care. 2015; 15:e040.

17. Sbarouni V, Tsimtsiou Z, Symvoulakis E, Kamekis A, Petelos E, Saridaki A, et al. Perceptions of primary care professionals on quality of services in rural Greece: a qualitative study. Rural Remote Health. 2012;12:2156.

18. Girvalaki C, Papadakis S, Vardavas C, Pipe A, Lionis C. Tobacco treatment TrAining Network in Crete (TiTANCrete): Protocol for a controlled before-after study. Tob Prev Cessation. 2016;2:57.

19. Symvoulakis E, Klinis S, Kakoliris N, Karamitrou D, Vardavas C, Lionis C. The association between tobacco use and perceptions of tobacco price strategies within primary care patients in rural Greece. Tob Prev Cessation. 2016,2:53.

20. Lionis C, Petelos E. The impact of the financial crisis on the quality of care in primary care: an issue that requires prompt attention. Qual Prim Care. 2013;21:269-273.

21. Hou X, Velényi EV, Yazbeck AS, Lunes RF and Smith O. Learning from economic downturns: How to better 
assess, track, and mitigate the impact on the health sector, Washington DC: World Bank, 2013.

22. Justo M. Access to medicines in Greece - A patient view from Greece. PatientView Quarterly. June 2013.

23. European Commission. Interoperable eHealth is worth it. Securing benefits from Electronic Health Records and ePrescribing. Study Report, 2010. Available from: http:// ec.europa.eu/digital-agenda/en/news/interoperable-ehealthworth-it-securingbenefits-electronic-health-records-andeprescribing-02.

24. Moen A, Hackl WO, Hofdijk J, Van Gemert-Pijnen L, Ammenwerth E, Nykänen P, Hoerbst A. eHealth in Europe Status and Challenges. EJBI 2012; 8:2-7.

25. Kounalakis DK, Lionis C, Okkes I, Lamberts H. Developing an appropriate EPR system for the Greek primary care setting. J Med Syst. 2003;27:239-246.

26. Baker JL. Direction in development: evaluating the impact of development projects on poverty. A Handbook for Practitioners. Washington, D.C.: The World Bank, 2000.

27. Kontodimopoulos N, Nanos P, Niakas D. Balancing efficiency of health services and equity of access in remote areas in Greece. Health Policy. 2006;76:49-57.

28. Heath I, Rubinstein A, Stange KC, van Driel ML. Quality in primary health care: a multidimensional approach to complexity. BMJ. 2009;338:b1242.

29. Ministry of Health. Conference Dialogue for Reform in Primary Health Care in Greece, 2016. Available from: http:// www.moh.gov.gr/articles/ministry/grafeio-typoy/pressreleases/3907-dihmerida-dialogoy-gia-th-metarrythmishsthn-prwtobathmia-frontida-ygeias 